\title{
BMJ Open Diagnostic role of urine specific gravity to detect kidney impairment on heat-exposed workers in a shoe factory in Indonesia: a cross-sectional study
}

\author{
Ginova Nainggolan (D) , ${ }^{1}$ Dewi Soemarko, ${ }^{2}$ Parlindungan Siregar, ${ }^{1}$ Aida Lydia, ${ }^{1}$ \\ Saptawati Bardosono, ${ }^{3}$ Ani Retno Prijanti, ${ }^{4}$ Diana Aulia ${ }^{5}$
}

To cite: Nainggolan G, Soemarko D, Siregar $P$, et al. Diagnostic role of urine specific gravity to detect kidney impairment on heatexposed workers in a shoe factory in Indonesia: a crosssectional study. BMJ Open 2021;11:e047328. doi:10.1136/ bmjopen-2020-047328

- Prepublication history for this paper is available online. To view these files, please visit the journal online (http://dx.doi org/10.1136/bmjopen-2020047328).

Received 28 November 2020 Accepted 13 September 2021

Check for updates

(c) Author(s) (or their employer(s)) 2021. Re-use permitted under CC BY-NC. No commercial re-use. See rights and permissions. Published by BMJ.

For numbered affiliations see end of article.

Correspondence to Dr Ginova Nainggolan; ginovan@hotmail.com

\section{ABSTRACT}

Objectives Globally, there are increasing cases of chronic kidney disease of unknown origin among heat-exposed workers. We aimed to see the kidney damages of indoor heat-exposed workers and whether urine specific gravity can predict any kidney damages.

Design A cross-sectional study.

Setting A shoe-making factory in West Java, Indonesia. Participants 119 subjects were included. Minimum total sample size was 62 . Subjects were indoor heat-exposed workers who were exposed to occupational wet-bulb globe temperature (WBGT) of $28^{\circ} \mathrm{C}-30^{\circ} \mathrm{C}$ for 8 hours daily with 1 hour break, 5 days a week. The inclusion criterion was healthy subjects according to the result from annual medical check-up in 2019. The exclusion criteria were subjects who were taking vitamins and/or supplements that might cause disturbance in urine specific gravity and/ or hydration status, pregnant and fasting.

Primary and secondary outcome measures Area under the curve (AUC), sensitivity and specificity of urine specific gravity for the detection of urinary nephrin and urinary kidney injury molecule-1 (KIM-1) were analysed. Estimated glomerular filtration rate (eGFR) and quantitative albuminuria were also measured.

Results WBGT in the work area of the subject was $28^{\circ} \mathrm{C}-30^{\circ} \mathrm{C}$. There were $15(12.6 \%)$ subjects who had eGFR $<90 \mathrm{~mL} / \mathrm{min}$, but $\geq 60 \mathrm{~mL} / \mathrm{min}$. High serum vasopressin levels were found in 79 subjects with a mean of 6.54 (95\% Cl 5.94 to 7.14$) \mathrm{ng} / \mathrm{mL}$. Most subjects had nephrinuria (87.4\%) with preserved renal function (87.4\%). Several subjects had elevated urinary KIM-1 (10.9\%) and albuminuria (7.6\%). AUC of urine specific gravity for increased urinary nephrin was $81.7 \%$ (95\% Cl 68.8\% to $94.6 \%)$ and statistically significant $(p<0.001)$. Cut-off value of $\geq 1.018$ for urine specific gravity has sensitivity of $71.2 \%$ and specificity of $80 \%$ for detecting elevation of urinary nephrin levels.

Conclusion Urine specific gravity with a cut-off value of $\geq 1.018$ could be used to detect nephrinuria among heat-exposed workers.

\section{INTRODUCTION}

Indonesia is an archipelago country which is located along the equator in Southeast Asia. It has a diverse environmental temperature.
Strengths and limitations of this study

- Novel biomarkers of kidney damages (urinary nephrin and kidney injury molecule-1) were examined along with estimated glomerular filtration rate and urinary albumin.

- The study was conducted in subjects with clear medical history data due to the annual medical check-up.

- Blood and urine specimens were collected when the subjects were working in heat-exposed area.

- To avoid disturbing the factory working rhythm, random sampling was not possible to be done.

- No control group.

In some urban areas, the mean annual temperature is $25.8^{\circ} \mathrm{C}$, but may reach as high as $30.2^{\circ} \mathrm{C} .{ }^{1}$ With the ongoing climate change, the temperature is projected to increase $0.3^{\circ} \mathrm{C}$ per decade. ${ }^{1}$ In 2015 , Indonesia is reported to have 303 heat stress days, one of the highest among countries in Southeast Asia. ${ }^{2}$ This number is expected to continue rising to 355 heat stress days in 2045. Heat stress days are the number of days per year when the temperature, which is measured by wet-bulb globe temperature (WBGT), reached the unsafe levels (ranging from $>32.5^{\circ} \mathrm{C}$ WBGT for light work activity to $>28^{\circ} \mathrm{C}$ WBGT for very vigorous work activity). ${ }^{3}$ Other reports also similarly showed that the WBGT for indoor workers in Indonesia will keep increasing. ${ }^{45}$

Heat stress, which is defined as combination of body heat from metabolic and environmental factors, poses a health risk to indoor workers. ${ }^{67}$ Although indoor workers are not exposed to direct sunlight, those who are working in the vicinity of heatproducing machines or instruments may experience similar heat stress. With excessive or prolonged heat stress, the body cooling mechanism, mainly through sweating, may 
fail. ${ }^{8}$ As a result, the body temperature rises and pathological changes ensue. In the short-term, heat stress can cause heat-related illness, ranging from mild reversible symptoms to fatal complications. ${ }^{8}$

The Indonesian government has regulated the allowed WBGT, maximum physical activity and minimum restwork ratio for heat-exposed workers, along with the recommended protective measures, such as drinking $200-300 \mathrm{~mL}$ of water every $15 \mathrm{~min} .{ }^{3}$ However, reports from local studies showed that the indoor industries did not fully conform to it. ${ }^{9-11}$ In one study, the indoor WBGT reached $34.9^{\circ} \mathrm{C}$, which has far exceeded the maximum allowed temperature (the study used upper limit of $30.5^{\circ} \mathrm{C}$ WBGT per government regulation). ${ }^{11}$ On the other hand, the local industries compliance toward the recommended rest-work ratio and drinking frequency is unknown due to the lack of available publication. With the projected increase of temperature, those heat-exposed workers may be in danger of higher risk of heat stress in the future.

At one side, heat-related illness due to heat stress fortunately can be treated with simple oral rehydration and avoidance of heat source as soon as possible while the symptom is still mild. ${ }^{812}$ On the other side, recently there is a concern on the subclinical effect of chronic heat exposure, especially to kidney ${ }^{13-16}$ At first, the risk of kidney disease, such as acute kidney injury (AKI), is thought to be reversible and can be averted with a quick management before progressing to a more severe stage. ${ }^{8}{ }^{12}$ However, several reviews highlight that occupational heat stress possibly causes repetitive subclinical ischaemic kidney injury which may eventually progress to chronic kidney disease (CKD) ${ }^{13-16}$ Without obvious symptom, such kidney injury may progress unnoticeable. Other than this hypothesised direct route, recurrent heat exposure may also indirectly lead to CKD by increasing the risk of kidney stone. ${ }^{1317}$

Appropriate screening can be used as a method for prevention of CKD in high-risk individuals like heatexposed workers. The standard screening tests for CKD are serum creatinine and urine albumin for measurement of kidney function and kidney damage, respectively. ${ }^{18}$ However, when serum creatinine or urine albumin levels are abnormal, CKD is already set afoot. Various promising novel biomarkers have been introduced to detect early kidney injury in heat-exposed workers. ${ }^{19}$ Two examples of these markers are urinary nephrin and kidney injury molecule-1 (KIM-1). Urinary nephrin is used to detect glomerular damages, while urinary KIM-1 is used to detect tubular damages. ${ }^{20}{ }^{21}$ Urinary KIM-1 has been used to detect tubular injury in outdoor heat-exposed workers, while urinary nephrin is mostly used for individuals with glomerular diseases. ${ }^{19}{ }^{21}$ Both tests precede the incident of increased serum creatinine and microalbuminuria. ${ }^{21} 22$

The applicability of urinary nephrin and KIM-1 tests for heat-exposed workers is still limited because they are expensive and not widely used in clinical setting. An inexpensive surrogate test, which can accurately detect these early kidney injury biomarkers in heat-exposed workers, is needed. Urine specific gravity perhaps can be the answer. Urine specific gravity is commonly used to detect dehydration with $\geq 1.020$ as cut-off value. ${ }^{23}{ }^{24}$ According to our knowledge, there is no previous research that has studied the ability of urine specific gravity to detect increased urinary nephrin or KIM-1.

This study was conducted with two sequential primary objectives and a secondary objective. The first objective was to know whether there was early kidney injury (marked by increased urinary nephrin and/or KIM-1) in indoor heat-exposed workers. The subsequent primary objective was to evaluate the diagnostic role of urine specific gravity for detecting early kidney injury in those indoor heat-exposed workers. The secondary objective of this study was to identify whether those heat-exposed workers also have increased serum vasopressin and albuminuria, and whether urine specific gravity can detect them.

\section{MATERIALS AND METHODS}

\section{Study design and setting}

This was a cross-sectional study in a shoe-making factory, which had 13000 workers, in West Java, Indonesia. Data were obtained through consecutive sampling in March 2020 (before the start of COVID-19 pandemic in Indonesia). The use of random sampling and control group was not possible due to the agreement with the factory management, in order to avoid disturbance to the working rhythm of the factory.

\section{Participants}

The subjects were workers who were assigned to the hotpress machines in morning shift and exposed to $\geq 28^{\circ} \mathrm{C}$ WBGT for 8 hours daily with 1 hour break, 5 days a week. To be eligible for this study, the subjects must fulfil the following inclusion criteria: age 30-50 years old, had worked in the hot-press machines area for at least 3 years, not on any routine medication at least 1 month before data collection, had normal serum creatinine and urinalysis in November 2019 annual medical check-up and had never been diagnosed with hypertension, diabetes, cardiovascular disease, cancer and kidney disease. Subjects who were having any of the following exclusion criteria were ineligible for this study: taking vitamins and/ or supplements that might affect the urine specific gravity result and/or hydration status, pregnant and fasting. All subjects provided written informed consent before participating in the study. According to the agreement, subjects were chosen consecutively by factory management.

\section{Eligible subjects}

From approximately 13000 workers in the factory, 2998 of them were working near hot-press machines and exposed to heat. Approximately half of them were working in morning shift, while the rest were working in night shift. Subjects were chosen only from the morning shift, which had higher WBGT due to higher air temperature. Sixty 


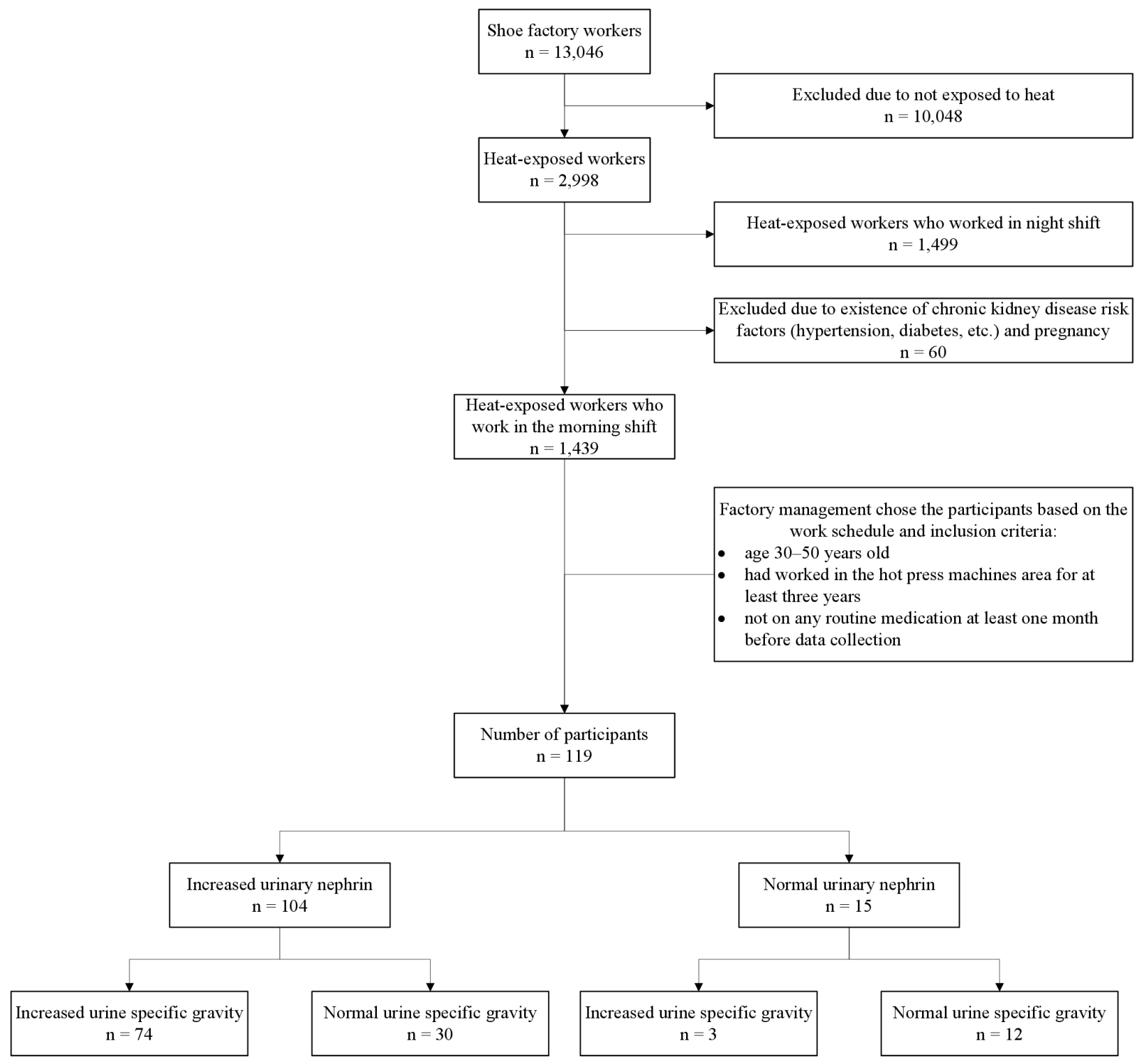

Figure 1 Flow of participants.

subjects were excluded due to hypertension, diabetes and pregnancy. Therefore, the total number of eligible subjects was 1439 . The minimum required sample size was 62 subjects. To make sure the study was not underpowered, we tried to approximately double the number of samples. Therefore, in the end, 119 subjects participated in the study. The overall subject selection process is shown in figure 1 .

\section{Drinking compliance of subjects}

To objectively measure drinking compliance of the subjects, a combination of two tests were used, that is, urine specific gravity and serum vasopressin.

\section{Data collection}

Field data collection was conducted on 6, 9, 13 and 16 March 2020. The author (GN) and field team, which consisted of six skilled laboratory professionals, interviewed the subjects and collected the blood and urine specimens. Subjects were interviewed for gender, age and length of service. After a period of work-rest-work (4hours of work, 1 hour of rest, then another 1 hour of work) with hot-press machines, blood samples were taken from the subjects when they were working. Urine samples were collected with clean catch method. Urine containers were given to subjects and they were instructed to return the urine-filled containers immediately. From blood and urine samples, several laboratory parameters were checked, that is, serum creatinine, estimated glomerular filtration rate (eGFR) with CKD Epidemiology Collaboration equation, serum vasopressin, urine dipstick albumin, urinary nephrin and urinary KIM-1. To confirm albuminuria, those who had negative results on dipstick tests were further checked with urine albumincreatinine ratio (ACR) using the same urine specimens. Additionally, management of the factory was interviewed to gain overall insight on the working condition in the factory. 


\section{Test methods}

All assays were performed in a standardised laboratory. Serum vasopressin levels were assessed with quantitative sandwich enzyme immunoassay (Nordic Biosite) by using biotin antibody reagent and streptavidin-horseradish peroxidase conjugate working solution. Urinary KIM-1 levels were assessed with quantitative sandwich enzyme immunoassay reagent calibrator diluent RD6Q (Exocell). Urinary nephrin levels were assessed with quantitative sandwich enzyme immunoassay by using anti-hu nephrin antibody (Exocell). Serum vasopressin, urinary nephrin and urinary KIM-1 examination were performed according to the manufacturers' instructions. Urine specific gravity was measured qualitatively with urinary dipstick.

Serum vasopressin, urinary KIM-1 ${ }^{25}$ and urinary nephrin $^{25}$ were categorised as increased or abnormal if $>5 \mathrm{ng} / \mathrm{mL},>941 \mathrm{pg} / \mathrm{mL}$ and $>444 \mathrm{ng} / \mathrm{mL}$, respectively. Urine specific gravity was considered as abnormal if $\geq 1.0200 .^{23} \mathrm{eGFR}$ was considered decreased or abnormal if $<90 \mathrm{~mL} / \mathrm{min} / 1.73 \mathrm{~m}^{2}{ }^{18}$ Albumin was categorised as abnormal if the dipstick test was positive or urine ACR $\geq 30 \mathrm{mg} / \mathrm{g}$.

\section{Data analysis}

Statistical analysis was performed with IBM SPSS V.25 software. Normality of the data was assessed by KolmogorovSmirnov test. Numerical data with normal distribution were shown as mean, while the rests were shown as median. Categorical analysis used $\chi^{2}$ test with Fisher-Exact test as an alternative.

In determining the role of urine specific gravity as an early diagnostic tool for renal impairment, receiver operating characteristic (ROC) curve analysis was performed to evaluate urine specific gravity and other urinary markers. The sample size was determined with area under the ROC curve (AUC) sample size equation. As a result, a minimum of 62 samples was needed.

\section{Patient and public involvement}

Patients or the public were not involved in the design, or conduct, or reporting, or dissemination plans of our research.

\section{RESULTS}

\section{Factory condition}

There were seven main sections in the shoe factory, that is, rubber mill, hot-press machine, trimming and skiving, stock fit, cutting, stitching and assembling section. From all of them, only workers in hot-press machine area were exposed to heat. The whole production process was going continuously for 24 hours. Workers worked in two shifts, that is, morning and night shifts.

Almost all workers in hot-press machine area were women. The WBGT in the hot-press machine area was $30^{\circ} \mathrm{C}$. Annual temperature measurement by factory management showed that the WBGT in the hot-press machine area was ranging from $28^{\circ} \mathrm{C}$ to $30^{\circ} \mathrm{C}$. All heatexposed workers worked for 8 hours/day for five consecutive days per week. Those workers were also required to take a break outside the hot-press machine area for 1 hour after 4 hours of work. Moreover, the workers were also instructed to drink $200-300 \mathrm{~mL}$ of water every $15 \mathrm{~min}$ as per government regulation. The water was supplied by the factory management.

New workers in hot-press machine area must undergo the process of acclimatisation before being allowed to work fulltime. Therefore, to avoid frequent need for acclimatisation for new workers, workers in hot-press machine area were rarely transferred to other departments. Those heat-exposed workers had annual medical check-up, including serum creatinine and urine albumin tests. Those who had abnormal results were transferred to other departments.

\section{Main results}

Demographic and laboratory parameters of the subjects are shown in table 1. Most subjects had increased serum vasopressin levels (79 of 119 subjects) and increased urinary nephrin (104 of 119 subjects). The serum vasopressin levels had normal distribution, with a mean of $6.54(5.94-7.14) \mathrm{ng} / \mathrm{mL}$, which was above the upper limit of normal $(>5 \mathrm{ng} / \mathrm{mL})$.

From 110 subjects who had negative dipstick albuminuria, all except three underwent urine ACR test. Those three had inadequate urine samples and therefore, they were unable to be processed in laboratory machine for urine ACR. From 107 subjects whose samples underwent urine ACR test, one of them had urine ACR $\geq 30 \mathrm{mg} / \mathrm{g}$ and subsequently categorised as albuminuria, while the others had urine ACR $<30 \mathrm{mg} / \mathrm{g}$.

From this data, we analysed the AUC of urine specific gravity for each laboratory parameter (shown in figure 2). All of them were statistically non-significant, except for urinary nephrin $(\mathrm{p}<0.001)$. AUC of urine specific gravity for urinary nephrin was $81.7 \%$ (95\% CI $68.8 \%$ to $94.6 \%$ ). Furthermore, cut-off value of $\geq 1.018$ for urine specific gravity had a sensitivity of $71.2 \%$ and specificity of $80 \%$ for detecting elevation of urinary nephrin levels.

\section{Additional analysis}

We decided to perform additional analysis to evaluate whether there is an association between increased urinary nephrin and KIM-1 with eGFR and albuminuria. There was a statistically significant association between increased urinary KIM-1 and albuminuria $(\mathrm{p}=0.008)$, but no other statistically significant association was found. The association is shown in table 2.

\section{DISCUSSION}

\section{Principal findings}

According to our knowledge, our research was the first that study urinary nephrin and KIM-1 as the biomarkers for early kidney injury in indoor heat-exposed workers. 
Table 1 Quantitative and categorical results of demographic and laboratory parameters data

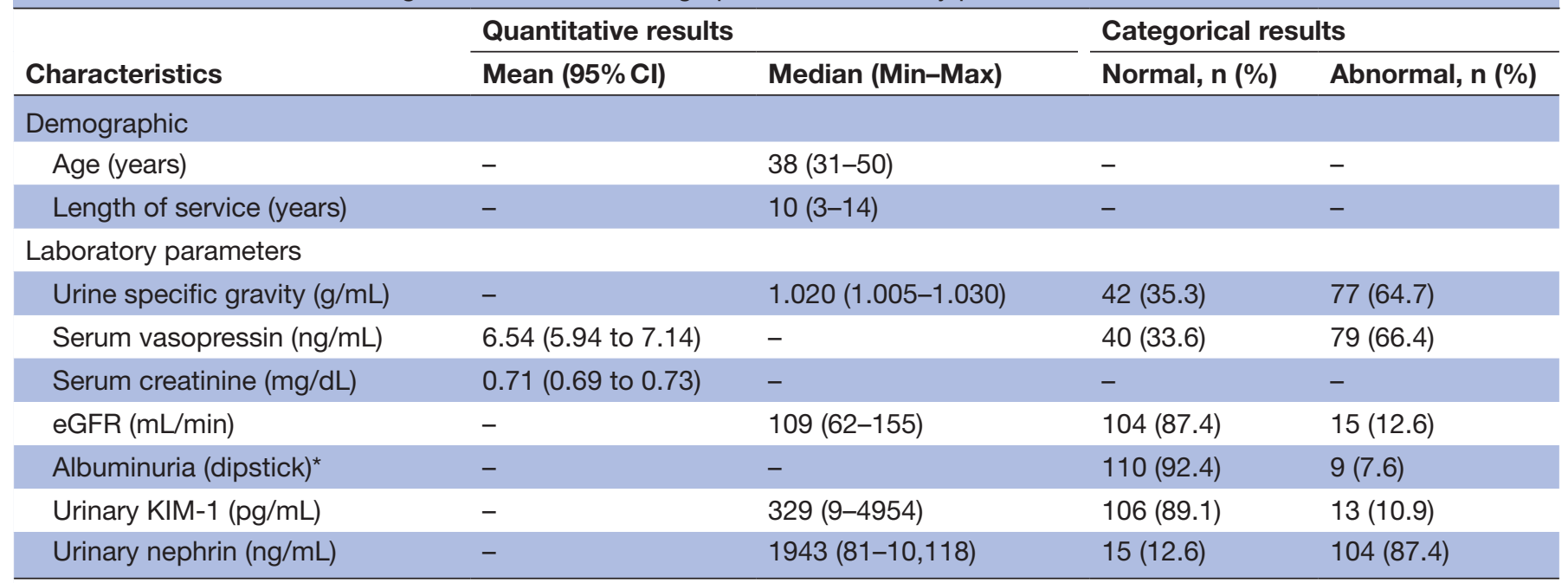

*106 had urine $A C R<30 \mathrm{mg} / \mathrm{g}, 1$ had urine $A C R \geq 30 \mathrm{mg} / \mathrm{g}$ and 3 had urine specimens which were insufficient for the test. ACR, albumin-creatinine ratio; eGFR, estimated glomerular filtration rate; KIM-1, kidney injury molecule-1.

Urinary nephrin levels were found to be elevated in most subjects $(87.4 \%)$ and urinary KIM-1 levels were elevated in a small number of subjects $(10.9 \%)$. Urine specific gravity was not associated with urinary KIM-1, but it had a moderate sensitivity and specificity for increased urinary nephrin. Most subjects had increased urine specific gravity and serum vasopressin, which indicated dehydration. A small number of subjects had eGFR less than $90 \mathrm{~mL} / \mathrm{min}$, but it is not sufficient to be diagnosed as CKD $(\geq 60 \mathrm{~mL} /$ min). In this study, all subjects were exposed to heat with $28^{\circ} \mathrm{C}-30^{\circ} \mathrm{C}$ WBGT for years (at least 3 years with a median of 10 years).

\section{Prevalent nephrinuria as a marker of glomerular disease among subjects}

The prevalent nephrinuria in this study warranted a special attention because it was supposed to be found in individuals with glomerular disease. Nephrin is one of many proteins which is expressed in the slit diaphragm at the glomerulus of the kidneys. ${ }^{21}$ It has a vital role in maintaining the integrity and function of the glomerular filtration barrier. ${ }^{21}$ The increase of nephrin in urine was associated with worse kidney function and albuminuria in various glomerular diseases. ${ }^{21}$ In normoalbuminuric early diabetic nephropathy, it can be used to predict the incidence of microalbuminuria. ${ }^{21}$ In other glomerular diseases, including membranous nephropathy and IgA nephropathy, urinary nephrin was correlated with the increased of albuminuria degree and kidney function decline rate. ${ }^{21}$ On the other hand, the prevalent nephrinuria among subjects in our study was not associated with lower eGFR or albuminuria.

Increased urinary KIM-1, the other novel kidney biomarker In this study, there was a small number of subjects who had increased urinary KIM-1, which had statistically significant association with albuminuria. KIM-1 is a glycoprotein which is predominantly expressed in proximal tubule cells of the kidneys. ${ }^{22} \mathrm{KIM}-1$ is normally detected in low level in the urine, but may acutely increase in AKI and precede the increase of serum creatinine level. ${ }^{22}$ Urinary KIM-1 was associated with incidence of CKD. ${ }^{22}$

In our study, there was no case of AKI according to the definition by Kidney Disease Improving Global Outcomes. ${ }^{26}$ Therefore, the finding of increased urinary KIM-1 was not related to AKI or decreased eGFR. On the other hand, because increased urinary KIM-1 in our study was associated with albuminuria $(\mathrm{p}=0.008)$, it was perhaps more due to albuminuria as shown in previous studies. ${ }^{27} 28$ Increased resorption of unfiltered albumin at proximal tubules may damage the tubular cells, which in turn increases urinary KIM-1. ${ }^{28}$

\section{Hydration status of the subjects}

In this study, we used combination of urine specific gravity and serum vasopressin to evaluate hydration status of the subjects. From physiological perspective, heat exposure will increase overall body temperature. To compensate, main cooling mechanism via sweating is activated. ${ }^{8}$ However, too much sweating subsequently increases plasma osmolality and stimulates the release of vasopressin into circulation. Vasopressin works in the tubules of kidneys by increasing water absorption from urine compartment. In the end, urine specific gravity increases. ${ }^{29}$

In our study, $64.7 \%$ of the subjects had increased urine specific gravity $\geq 1.020$, indicating that they were dehydrated. This finding was also complemented by increased serum vasopressin in $66.4 \%$ of the subjects. In other words, more than half of the subjects did not drink enough water as recommended by the factory management. 


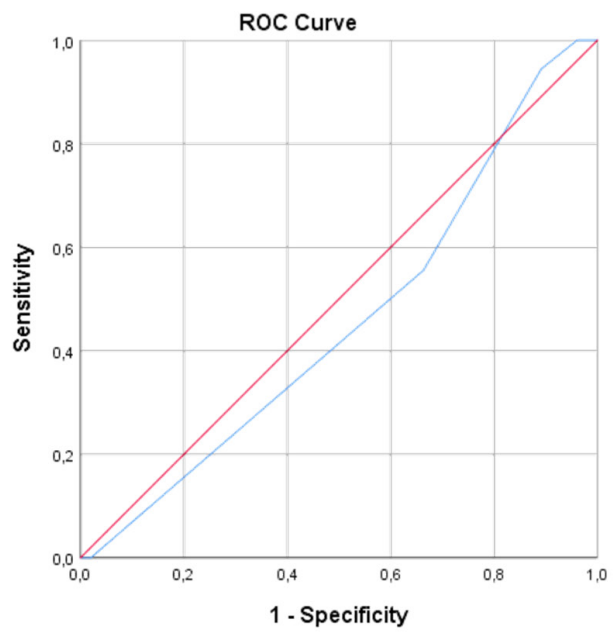

Diagonal segments are produced by ties

C

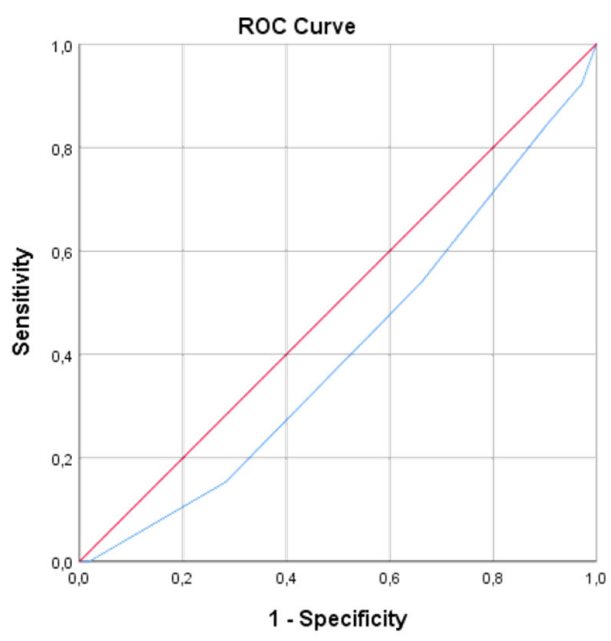

Diagonal segments are produced by ties.
B

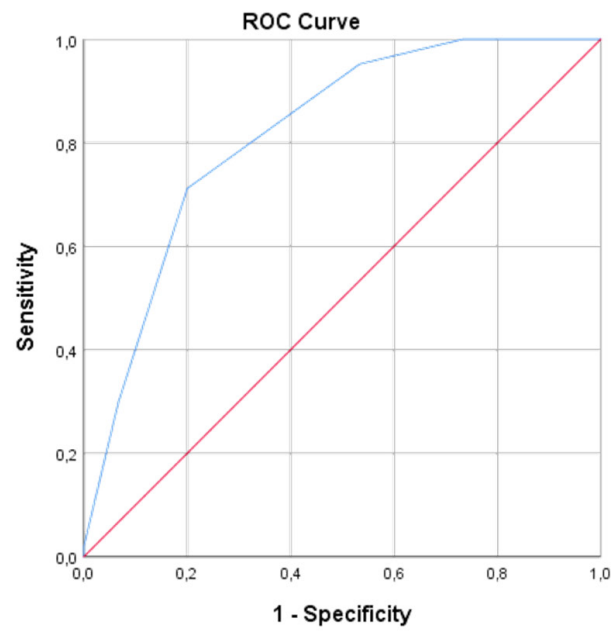

Diagonal segments are produced by ties

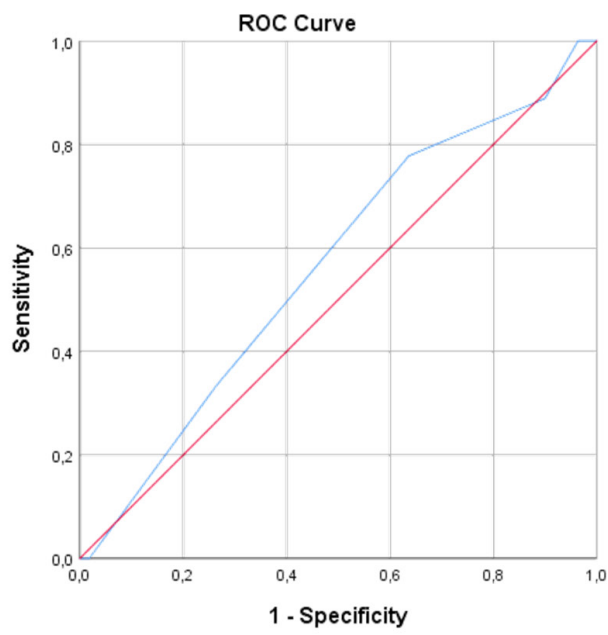

Diagonal segments are produced by ties. 


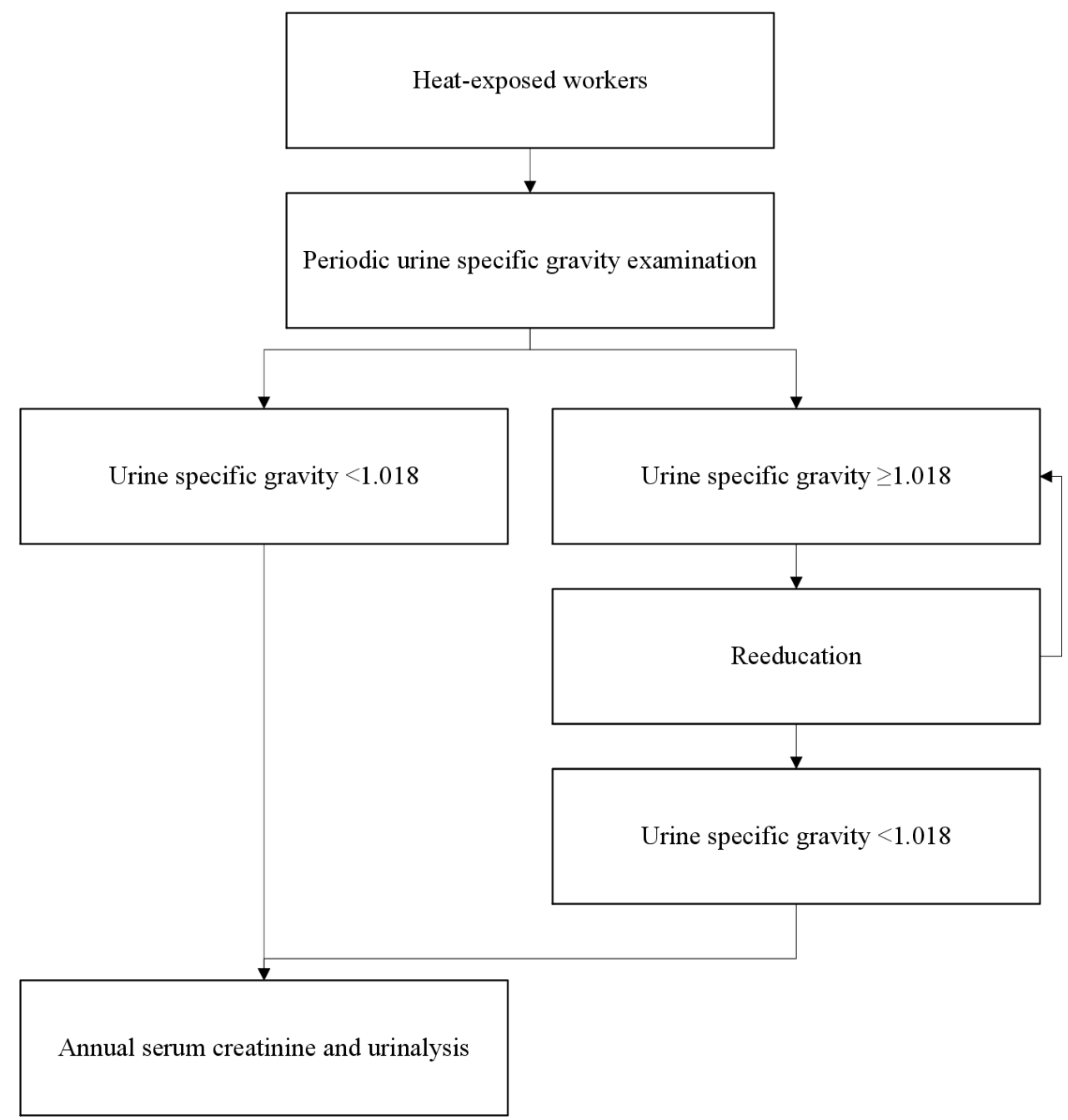

Figure 3 Proposed algorithm for detecting early kidney impairment in heat-exposed workers.

predictor of nephrinuria. Moreover, urine specific gravity test is easy to perform, cheap and can be done periodically in heat-exposed workers. Therefore, we would like to propose a screening algorithm for detecting early kidney impairment in heat-exposed workers (figure 3).

\section{Possible confounder and limitations}

Our study had limitations. First, due to the limited funding, we relied on the annual medical check-up data, which was provided by the factory management, for inclusion criterion. Because of the same reason, albuminuria was only measured by urinary dipstick. Next, physical examination, random sampling and the use of control group cannot be performed in our study due to restriction from factory management. Another limitation was all subjects were women. There is also a possibility that 'healthy worker effect' was present in our study; because the workers in our study have been screened regularly and worked for several years, they may have healthier kidneys compared with the workers who were transferred. Finally, the cross-sectional nature of our study limited the intervariable association which can be concluded, including the causal-effect relation between nephrinuria and chronic heat exposure.
Larger prospective study with greater funding is needed to confirm our findings. Compensation for the factory's loss of productivity due to the study may be needed as a counterbalance to a more ideal study design.

\section{CONCLUSION}

In our study, nephrinuria was prevalent among workers who were exposed to heat for at least 3 years. However, whether the cause of prevalent nephrinuria in this study was chronic exposure or not was unknown. From diagnostic analysis, urine specific gravity with cut-off value of $\geq 1.018$ had a moderate sensitivity and specificity to detect nephrinuria in heat-exposed workers.

\section{Author affiliations}

${ }^{1}$ Division of Nephrology, Department of Internal Medicine, Faculty of Medicine Universitas Indonesia-Cipto Mangunkusumo National General Hospital, Jakarta, Indonesia

${ }^{2}$ Division of Occupational Medicine, Department of Community Medicine, Faculty of Medicine Universitas Indonesia-Cipto Mangunkusumo National General Hospital, Jakarta, Indonesia

${ }^{3}$ Department of Nutrition, Faculty of Medicine Universitas Indonesia-Cipto

Mangunkusumo National General Hospital, Jakarta, Indonesia 
${ }^{4}$ Department of Biochemistry and Molecular Biology, Faculty of Medicine Universitas Indonesia-Cipto Mangunkusumo National General Hospital, Jakarta, Indonesia ${ }^{5}$ Department of Clinical Pathology, Faculty of Medicine Universitas Indonesia-Cipto Mangunkusumo National General Hospital, Jakarta, Indonesia

Acknowledgements We would like to thank Patria Wardana Yuswar for his help in writing the draft of the manuscript. We also thank Prodia Clinical Laboratory for providing a team of laboratory professional and the whole laboratory tests in this study.

Contributors GN carried out the research, analysed the data and wrote the report. DS, PS, AL, SB, ARP and DA supervised the research and report.

Funding This work was supported by Universitas Indonesia with grant number NKB-1284/UN2.RST/HKP.05.00/2020.

Competing interests None declared.

Patient and public involvement Patients and/or the public were not involved in the design, or conduct, or reporting, or dissemination plans of this research.

Patient consent for publication Not applicable.

Ethics approval This study had been approved by the Medical Ethics Committee, Faculty of Medicine Universitas Indonesia (KET-1206/UN.2F1/ETIK/ PPM.00.02/2019) and agreed on by the factory's management.

Provenance and peer review Not commissioned; externally peer reviewed.

Data availability statement Data are available upon reasonable request. The data underlying this article will be shared on reasonable request to the corresponding author.

Open access This is an open access article distributed in accordance with the Creative Commons Attribution Non Commercial (CC BY-NC 4.0) license, which permits others to distribute, remix, adapt, build upon this work non-commercially, and license their derivative works on different terms, provided the original work is properly cited, appropriate credit is given, any changes made indicated, and the use is non-commercial. See: http://creativecommons.org/licenses/by-nc/4.0/.

ORCID iD

Ginova Nainggolan http://orcid.org/0000-0001-7955-4169

\section{REFERENCES}

1 World Bank. Climate knowledge portal, 2021. Available: https://clim ateknowledgeportal.worldbank.org/country/indonesia/climate-datahistorical [Accessed 5 Apr 2021].

2 Maplecroft V. Heat stress threatens to cut labour productivity in SE Asia by up to $25 \%$ within 30 years, 2015 . Available: https:// www.maplecroft.com/insights/analysis/heat-stress-to-cut-labourproductivity-in-30-years [Accessed 7 Apr 2021].

3 Indonesian Ministry of Health. Peraturan Menteri Kesehatan Republik Indonesia Nomor 70 Tahun 2016 Tentang Standar DAN Persyaratan Kesehatan Lingkungan Kerja Industri, 2016.

4 Kjellstrom T, Lemke B, Otto M. Mapping occupational heat exposure and effects in south-east Asia: ongoing time trends 1980-2011 and future estimates to 2050. Ind Health 2013;51:56-67.

5 Kjellstrom T, Lemke B, Otto M. Climate conditions, workplace heat and occupational health in south-east Asia in the context of climate change. WHO South East Asia J Public Health 2017;6:15.

6 Cheung SS, Lee JKW, Oksa J. Thermal stress, human performance, and physical employment standards. Appl Physiol Nutr Metab 2016:41:S148-64.
7 Fatima SH, Rothmore P, Giles LC, et al. Extreme heat and occupational injuries in different climate zones: a systematic review and meta-analysis of epidemiological evidence. Environ Int 2021; $148: 106384$

8 Atha WF. Heat-Related illness. Emerg Med Clin North Am 2013;31:1097-108

9 Arianto P., Dwiyanti E. Subjective work fatigue due to hot work climate (a study on indoor production workers of Ud King RACK Surabaya Indonesia). Indian J Forensic Med Toxicol 2020;14.

10 Puspita N, Kurniawidjaja M, Hikmat Ramdhan D. Health effect symptoms due to heat stress among Gong factory workers in Bogor, Indonesia. KLS 2018:4:469.

11 Fajrianti G, Shaluhiyah Z, Lestantyo D. Pengendalian heat stress pada tenaga kerja di bagian furnace Pt. X Pangkalpinang Bangka Belitung. JPKI 2017:12:150.

12 Lipman GS, Gaudio FG, Eifling KP, et al. Wilderness medical Society clinical practice guidelines for the prevention and treatment of heat illness: 2019 update. Wilderness Environ Med 2019;30:S33-46.

13 Nerbass FB, Pecoits-Filho R, Clark WF, et al. Occupational heat stress and kidney health: from farms to factories. Kidney Int Rep 2017;2:998-1008.

14 Roncal-Jimenez C, Lanaspa MA, Jensen T, et al. Mechanisms by which dehydration may lead to chronic kidney disease. Ann Nutr Metab 2015;66 Suppl 3:10-13.

15 Roncal Jimenez CA, Ishimoto T, Lanaspa MA, et al. Fructokinase activity mediates dehydration-induced renal injury. Kidney Int 2014;86:294-302.

16 Bankir L, Bouby N, Ritz E. Vasopressin: a novel target for the prevention and retardation of kidney disease? Nat Rev Nephrol 2013;9:223-39.

17 Venugopal V, Latha PK, Shanmugam R, et al. Risk of kidney stone among workers exposed to high occupational heat stress - A case study from southern Indian steel industry. Sci Total Environ 2020;722:137619.

18 KDIGO. KDIGO 2012 clinical practice guideline for the evaluation and management of chronic kidney disease. Kidney Int Supp/ 2012;3:5-127.

19 Gunasekara TDKSC, De Silva PMCS, Herath C, et al. The utility of novel renal biomarkers in assessment of chronic kidney disease of unknown etiology (CKDu): a review. Int J Environ Res Public Health 2020;17:9522.

20 Yin C, Wang N. Kidney injury molecule-1 in kidney disease. Ren Fail 2016;38:1567-73.

21 Akankwasa G, Jianhua L, Guixue C, et al. Urine markers of podocyte dysfunction: a review of podocalyxin and nephrin in selected glomerular diseases. Biomark Med 2018;12:927-35.

22 Waanders F, van Timmeren MM, Stegeman CA, et al. Kidney injury molecule-1 in renal disease. J Pathol 2010;220:7-16.

23 Simerville JA, Maxted WC, Pahira JJ. Urinalysis: a comprehensive review. Am Fam Physician 2005:71:1153-62.

24 Kavouras SA. Assessing hydration status. Curr Opin Clin Nutr Metab Care 2002;5:519-24.

25 Sekulic M, Pichler Sekulic S. A compendium of urinary biomarkers indicative of glomerular podocytopathy. Patholog Res Int 2013:2013:1-18.

26 Khwaja A. KDIGO clinical practice guidelines for acute kidney injury. Nephron Clin Pract 2012;120:c179-84.

27 Huang Y, Tian Y, Likhodii S, et al. Baseline urinary KIM1 concentration in detecting acute kidney injury should be interpreted with patient pre-existing nephropathy. Pract Lab Med 2019;15:e00118.

28 Zhao X, Jiang C, Olufade R, et al. Kidney injury molecule-1 enhances endocytosis of albumin in renal proximal tubular cells. J Cell Physiol 2016;231:896-907.

29 Perrier ET. Shifting focus: from hydration for performance to hydration for health. Ann Nutr Metab 2017;70 Suppl 1:4-12. 